\title{
Error Analysis in the Written Compositions of EFL Students: A Classroom Study
}

\author{
Anjum Chaudhary ${ }^{1} \&$ Sahar Al Zahrani ${ }^{1}$ \\ ${ }^{1}$ Assistant professor, English Language Centre, Umm al-Qura University, Makkah, Saudi Arabia \\ Correspondence: Anjum Chaudhary, 3085, Muallifin street, Al Aziziyah district, Jeddah 22432-8144, Saudi \\ Arabia. E-mail: amchaudhary@uqu.edu.sa
}

Received: January 5, 2020 Accepted: February 3, 2020 Online Published: February 23, 2020

doi:10.5539/ijel.v10n2p357 URL: https://doi.org/10.5539/ijel.v10n2p357

\begin{abstract}
The aim of the study is to analyse the linguistic errors in the writings of EFL students in a Saudi university. For error analysis, the writing tasks of a group of students were collected and analysed. The results showed that the frequently committed errors were at the sentential level as well as the word level. The most frequent errors were the errors of spellings and the least were the errors of demonstratives. The marked errors were categorised as errors of omission, addition, misinformation and misordering. Further analysis of the collected data indicated interlingual interference, intralingual interference, inadequate practice in English writing and carelessness of students as the major sources of the errors. Hence, the study has pedagogical implications as it will help teachers to device appropriate measures for improving the students' writing proficiency.
\end{abstract}

Keywords: error analysis, interlingual interference, intralingual interference, EFL students, Saudi university

\section{Introduction}

It is evident from various research on Second Language Learning (SLL) that attaining good proficiency in SL is not an easy task. Of the four basic skills in SLL, writing skill seems to be less popular among language learners due to its difficulty level, as advocated by the several researchers (Rattanadilok Na Phuket \& Othman, 2015). It becomes a challenge for any language teacher to motivate SL learners to understand the importance of writing and to put enough effort to enhance their level of writing skill. The fact that all the communication done at any workplace needs good writing skills demonstrates the importance of writing skills. Moreover, university students are the potential aspirants of any job market. Thus, mastery of the writing skill can help students toward better educational and professional success. As Walsh (2010) says that writing has immense importance in higher education as well as at the professional level.

Apparently, students entering the preparatory year program at Umm Al Qura university have a low level of proficiency in English writing skills. Students seem to be reluctant to do their writing tasks in comparison to other language skills. After discussing this issue at length with the students, it was observed that they were afraid of making errors. Thus, to overcome this reluctance, it is a necessity for teachers to investigate the areas of problems and the reasons behind that. Therefore, the present study was carried out in line with Brown's (1993) assertion that feedback on learners' productive skills plays a vital role in learners' success.

\subsection{Research Objectives}

The main objectives of the present research are as follows:

1) To investigate the writing errors found in the performance of students in their classwork writing tasks.

2) To identify the frequency of writing errors made by EFL students in their classwork writing tasks.

3) To identify the sources of writing errors made by EFL students in their classwork writing tasks.

\subsection{Research Questions}

The present study aims to answer the following research questions:

1) What type of writing errors are committed by EFL students in their classwork writing tasks?

2) What is the frequency of writing errors in students' written tasks?

3) What are the sources of errors found in students' writing tasks? 


\subsection{Significance of the Study}

The study has a two-fold significance:

1) Firstly, it can help teachers to have insights into the learning process learners go through and the systematic analysis of the errors will enable them to find the actual sources of errors. Furthermore, it would provide a pedagogical advantage to employ appropriate methods for remedial measures (Corder, 1981).

2) Secondly, it would help students to know the areas which need further improvement in their English language learning process to achieve the target language learning objectives.

\section{Literature Review}

\subsection{Error Analysis (ER)}

The concept of Error Analysis was introduced by Stephen Pit Corder in the 1960s. Since then, several linguists and researchers have defined Error Analysis. To begin with, Corder (1981) defines Error Analysis (EA) as "the study and analysis of the errors made by second and foreign language learners", whereas David Crystal (1999) defines it in language teaching as "the study of the unacceptable forms produced by someone learning a language, especially a foreign language." In a nutshell, EA helps to enhance the understanding of errors found among language teachers and learners by indicating "how language is learned or acquired and what strategies or procedures the learner is employing in the discovery of the language" (Corder, 1967).

As per Corder's theory of EA (1974), the process of EA can be divided into the following five stages:

1) Selection of the language sample - it includes determining the size of the sample, the medium of the sample (oral or written) and homogeneity of the sample (background, age, and location).

2) Identification of errors in the sample — only errors should be identified not the mistakes.

3) Classification of errors - it is based on a variety of linguistic aspects i.e., Phonology, Morphology, Syntax, and Semantics.

4) Explanation of errors - it involves the identification of causes of errors i.e., interlingual, intralingual or developmental interference.

5) Evaluation of errors-it involves the assessment of the seriousness of the errors and it takes into consideration remedial decisions and pedagogical measures.

\subsection{Previous Studies on Error Analysis (ER)}

Various studies on Error Analysis (EA) are indicative of the magnitude of its importance for teachers as well as for learners. Different types of writings are being analysed by different researchers. They vary from sentence level to paragraphs, essays, abstracts, articles, etc. Some of the recently done studies are as follows:

Zheng and Park (2013) analysed the errors which occurred in English essays written by Chinese and Korean students. The results manifested that the errors for this sample included inappropriate use of articles, punctuation marks, and word order. They concluded that the major source of errors was intralingual interference.

In a comparative study, Khansir (2013) examined the types of errors committed by ESL and EFL students. He conducted the research on Indian students (ESL) and Iranian students (EFL). The results showed insignificant differences between the errors found in the writing of the two groups. Thus, he concluded that both ESL and EFL learners face similar problems in writing.

Al-Khasawneh (2014) investigated the writing errors which occurred in a corpus of 26 English paragraphs written by undergraduate university students in Jordon. The results of the study indicated that the most dominant error among the students was the inappropriate use of articles. The results also suggested various pedagogical implications.

Rattanadilok Na Phuket and Othman (2015) studied errors in narrative essays written by Thai undergraduate students and stated that the main cause of the errors was the negative transfer of students' L1.

Sermsook, Liamnimitr and Pochakorn (2017) examined language errors in 104 pieces of English written pieces by 26 second-year students in Thailand and explored the sources of the errors. Results showed that the most frequently committed errors were punctuation, articles, subject-verb agreement, spelling, capitalization, and fragment, respectively. The main sources of errors found were interlingual interference, intralingual interference, limited knowledge of English grammar and vocabulary, and carelessness of students. The study suggested that intensive teaching of English grammar and vocabulary should be considered with Thai EFL students

Khoso, Pathan and Shah (2018) through their study, investigated the most common errors committed by 
Pakistani students at the university level. Data were collected from 80 university teachers and were used to explore the perception of participants towards the grammatical errors committed by students. The feedback methods and the remedial measures were employed to correct these errors.

It can be concluded from the above-mentioned findings that the occurrence of errors in ESL and EFL writing is inevitable and is a universal phenomenon. Therefore, the researchers conducted the current study to find the frequency of errors that occurred in English writing tasks by Saudi EFL students. Besides, this study aims at examining the sources of errors and seeks to enhance students' awareness and understanding of the errors they commit.

\section{Methodology}

This section reviews the research methodology used in this research. It includes the research design, participants of the research, research instruments, research procedures, and data analysis.

\subsection{Research Design}

A mixed-method approach was used in the present study which combined the quantitative as well as the qualitative approach. A quantitative method was used to find out the frequency of errors, whereas two qualitative methods were employed to examine the in-depth knowledge of sources of errors.

\subsection{Participants}

This is a corpus-based study in which students' written tasks were collected and analysed. A group of fifteen female students in their preparatory year participated in this study. Most of the students had their primary education at public schools in which the Arabic Language was the medium of instruction, but English was taught as one of their subjects within the school curriculum. The students in this sample were enrolled in the advanced level of English for General Purposes course based on their performance in an English placement test administered at the beginning of the year. The subjects ranged from 17 to 20 years of age.

\subsection{Research Instrument}

As this is a classroom study, the sample is relatively small which represents an intact group. Non-random sampling method was employed to select the subject of this study. The sample encompasses 15 students. Ninety compositions were collected throughout the semester from female students who had English for General Purpose (EGP) as a compulsory subject. All the written tasks were administered by the researchers in the classroom. Also, more information was obtained from an online questionnaire and semi-structured interviews.

\subsection{Research Procedures}

In the present study, data were collected in different stages. First, all the 90 writing tasks were marked by the researchers and each error was recorded and classified. Then a questionnaire was administered to collect the information about sources of errors. Finally, each student was interviewed either individually or in a group to get in-depth and rich information related to the sources of errors.

\subsection{Data Analysis}

The data collected from all the used methods were analysed in two steps. First, all errors were identified and classified according to the types of errors known in the literature to get the frequency and the percentage of their occurrence. After that, each error type was classified into- sentence-level errors and word-level errors based on the linguistic category taxonomy. Further, the errors were categorised as per the surface structure taxonomy (Dulay, Burt, \& Krashen, 1982). Lastly, the interviews were interpreted, and the questionnaire data were analysed to obtain in-depth information related to the sources of errors.

\section{Results and Discussion}

In this section, the findings from all the collected data will be presented and discussed in accordance with the research questions posed in the study.

\subsection{Errors Frequently Occurring in English Writing Tasks by EFL University Students}

The analysis of errors shows that fifteen types of errors were found in English writing tasks done by EFL university students. The errors at the sentence level consist of punctuation, subject-verb agreement, capitalization, fragments, tenses, and word order. On the other hand, the errors at the word level were articles, nouns, pronouns, verbs, prepositions, adjectives, word choices, irregular verbs, and spellings. All the errors were further analysed and categorised as errors of addition, omission, misinformation and misordering. 
Table 1. Frequency, percentage, and rank of the errors committed

\begin{tabular}{|c|c|c|c|c|}
\hline & Types of Errors & Frequency & Percentage & Rank \\
\hline A & At sentence level & & & \\
\hline 1 & Tenses & 104 & $8.21 \%$ & 5 \\
\hline 2 & Subject-verb agreement & 21 & $1.66 \%$ & 10 \\
\hline 3 & Fragments & 108 & $8.52 \%$ & 4 \\
\hline 4 & Punctuation & 195 & $15.39 \%$ & 2 \\
\hline 5 & Capitalization & 187 & $14.76 \%$ & 3 \\
\hline \multirow[t]{2}{*}{6} & Word order & 15 & $1.18 \%$ & 11 \\
\hline & Total & 680 & & \\
\hline B & At word level & & & \\
\hline 7 & Articles & 45 & $3.55 \%$ & 8 \\
\hline 8 & Prepositions & 61 & $4.81 \%$ & 6 \\
\hline 9 & Nouns & 44 & $3.47 \%$ & 9 \\
\hline 10 & Pronouns & 11 & $0.87 \%$ & 12 \\
\hline 11 & Demonstratives & 1 & $0.08 \%$ & 14 \\
\hline 12 & Adjectives & 1 & $0.08 \%$ & 14 \\
\hline 13 & Word choice & 56 & $4.42 \%$ & 7 \\
\hline 14 & Spellings & 414 & $32.68 \%$ & 1 \\
\hline \multirow[t]{3}{*}{15} & Irregular verbs & 4 & $0.32 \%$ & 13 \\
\hline & Total & 587 & $100.00 \%$ & \\
\hline & Grand total & 1267 & & \\
\hline
\end{tabular}

The above table demonstrates types, frequency, percentage and rank of the errors. It shows that overall, the students committed 1,267 errors. Out of these errors, 680 were at the sentential level and 587 were at the word level which is clearly represented through the figures given below (Figures 1 and 2).

The most frequently occurring error type is spelling mistakes, corresponds to $32.68 \%$ of the total number of errors. This type is followed by punctuation $(15.39 \%)$, capitalization $(14.76 \%)$, fragments $(8.52 \%)$, tenses $(8.21 \%)$, prepositions $(4.81 \%)$, word choices $(4.42 \%)$, articles $(3.55 \%)$, nouns $(3.47 \%)$, subject-verb agreement $(1.66 \%)$, word order $(1.18 \%)$, pronouns $(0.87 \%)$, irregular verbs $(0.32 \%)$, demonstrative and adjective errors $(0.08 \%)$, respectively (as shown in Figures 1 and 2 ).

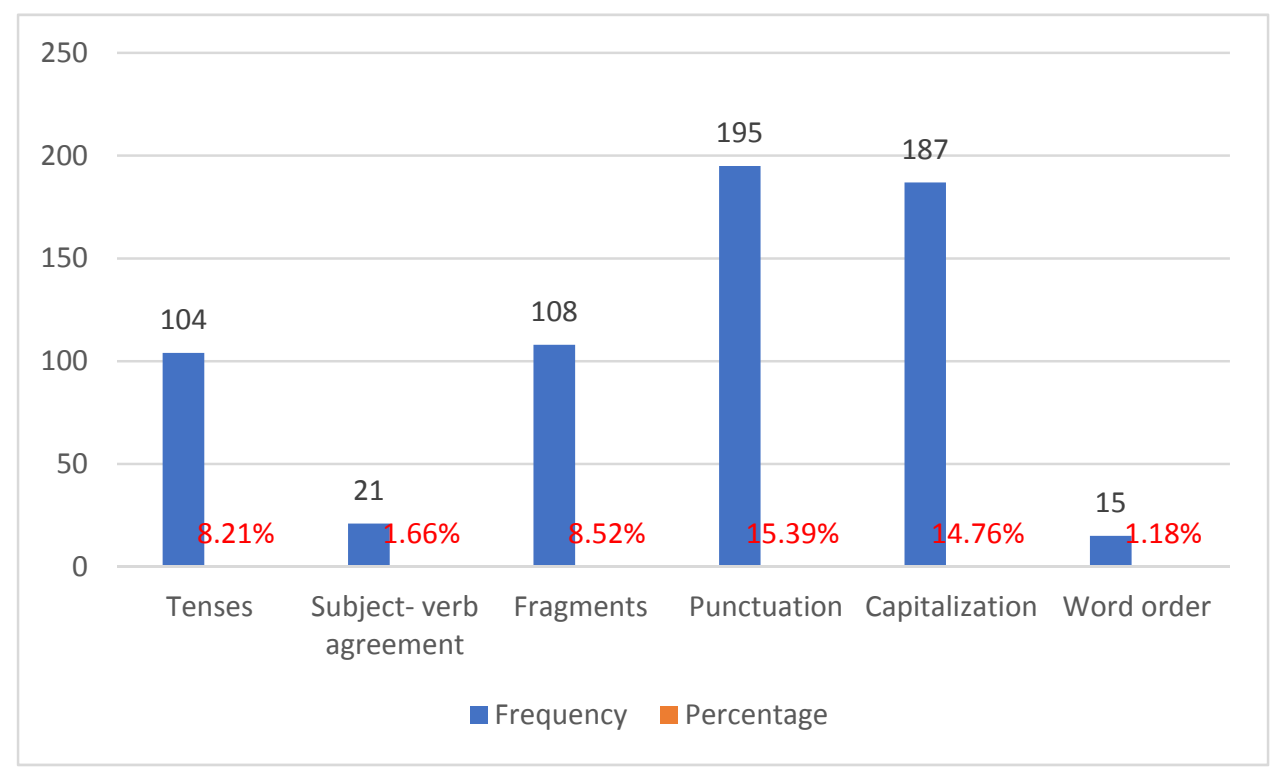

Figure 1. Types of errors at the sentence level 


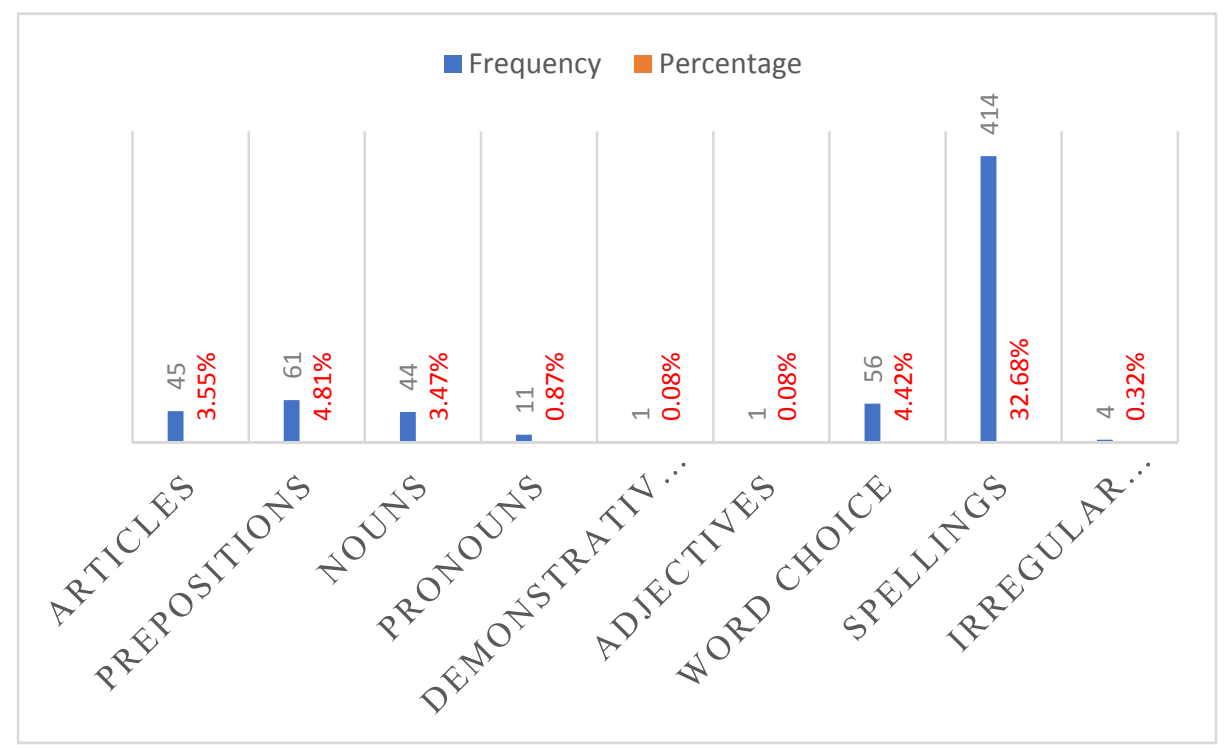

Figure 2. Types of errors at the word level

In-depth analysis indicates that errors of spellings, punctuations, capitalization, fragments, subject-verb agreement, tenses, prepositions, articles, and nouns were of considerable difficulty. This can be easily observed in Figure 3 which represents errors by their rank.

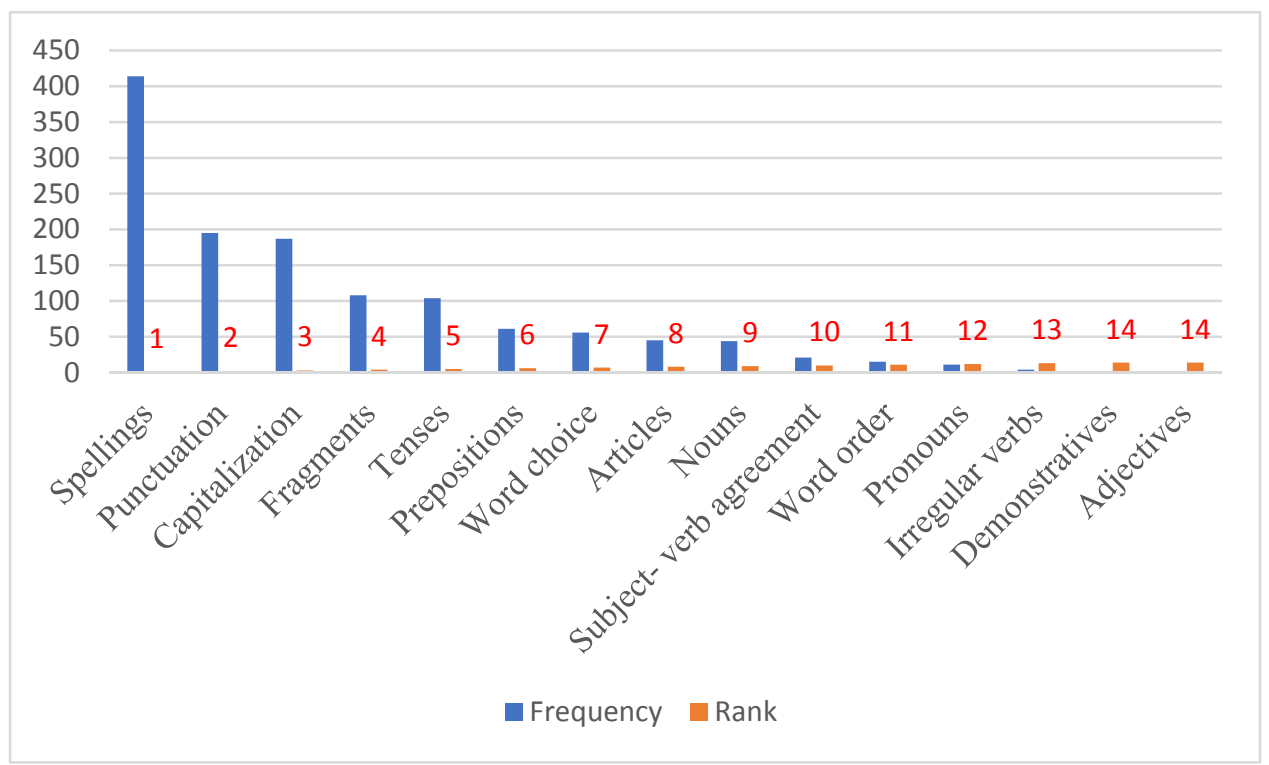

Figure 3. Types of errors by rank

\subsubsection{Spelling}

Errors of spelling were the majority as they represent more than one-third of the total errors. Most of the spelling errors were committed either by adding a letter or omitting a letter as evident in the following examples of sentences:

Example 1: There is one club in the collge.

Correct sentence: There is one club in the college.

Explanation: It's an error of omission i.e., letter 'e' was missing.

Example 2: I felt so much nerveous. 
Correct sentence: I felt so much nervous.

Explanation: It's an error of addition i.e. unnecessary use of letter 'e'.

Example 3: There are many restaurants neer the college.

Correct sentence: There are many restaurants near the college.

Explanation: It's an error of misinformation i.e. using incorrect letter.

The source of error in example 1 may be interlanguage interference as Arabic doesn't represent short vowels

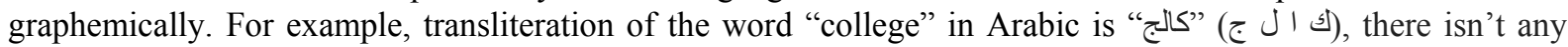
short vowel in it. However, the error in example 2 seems to be as a result of the limited knowledge of English vocabulary and carelessness on the part of the learner. Example 3 shows the negative influence of L2 the so-called interlanguage interference which may lead to the learner's confusion. She might be confused with the spelling rules of homophones such as 'deer' and 'dear'.

\subsubsection{Punctuation}

Next to the errors of spelling comes the errors of punctuation. The omission and the addition of comma (,) and period (.) were the second most frequent committed errors by the EFL learners. Here are a few examples from their writing:

Example 4: The weather is hot so make sure to have summer clothes.

Correct sentence: The weather is hot, so make sure to have summer clothes.

Explanation: A comma was omitted in this example which makes it an example of an error of omission.

Example 5: You can visit beautiful beaches and do water sports in the Arabian sea

Correct sentence: You can visit beautiful beaches and do water sports in the Arabian sea.

Explanation: In the above example, a period was omitted, and this makes it an error of omission.

Example 6: The college is located in the middle of Mecca city, The college

Correct sentence: The college is located in the middle of Mecca city. The college

Explanation: In the above sentence, a comma was used instead of a period between the two sentences. This is an error of misinformation.

The source of error in example 4 seems to be L1 interference because Arabic Language either reproduces the comma or inserts a lexical substitute. Thus, the learner with her inadequate knowledge of English might have applied the insertion of a lexical substitute while writing this English sentence. However, in examples 5 and 6 the students' limited knowledge of the related grammar rules might have led to the appearance of these errors. Even the study by Sermsook, Liamnimitr and Pochakorn (2017) shows the errors of punctuation marks as the most frequent errors.

\subsubsection{Capitalization}

A considerable number of errors of capitalization (14.76\%) were found in the writing produced by the learners. A few examples of such errors are as follows:

Example 7: on the day, I felt calm and relaxed.

Correct sentence: On the day, I felt calm and relaxed.

Explanation: A 'lower' case letter was used in the beginning of the sentence. This is an error of misinformation.

Example 8: I'm a business administration student.

Correct sentence: I'm a Business Administration student.

Explanation: An error of misinformation because a 'lower' case letter was used for the subject name.

Example 9: I was scared when i got into the building, so i forgot everything.

Correct sentence: I was scared when I got into the building, so I forgot everything.

Explanation: This is an error of misinformation because a 'lower' case letter was used for the pronoun "I" in the middle of the sentence. When the rule says the first-person singular pronoun is always capitalised in modern English.

The main source of errors in the above-mentioned examples is the L1 interference since the Arabic Language has no grammar rule which says to use 'upper' case letters (capitalization) for the first words in sentences and proper 
nouns. Moreover, the learner seemed to overgeneralise when she used 'lower' case "i" instead of 'upper' case "I" for the first- person singular nominative case personal pronoun, another pronoun was not capitalized except the one which comes at the beginning of a sentence. Therefore, it seems that the learner had limited knowledge of the English rule in this regard.

\subsubsection{Fragments}

This type of error can occur due to the absence of a subject or a verb. The following are the sample sentences from the learners writing:

Example 10: Three students learning English.

Correct sentence: Three students are learning English.

Explanation: The verb 'Be' (are) was omitted before the verb-ing in the present continuous tense. Therefore, this is an error of omission.

Example 11: It typically played with both hands.

Correct sentence: It is typically played with both hands.

Example12: The college located in the middle of Mecca.

Correct sentence: The college is located in the middle of Mecca.

Explanation: In sentence11 and 12, the verb 'Be'(is) was omitted in the present tense passive sentences. The type of these errors is errors of omission.

In all three examples, the errors which occurred were due to the Arabic language interference. The examples from students' writing do not have any verb 'Be' because the learners literally translated them from Arabic into

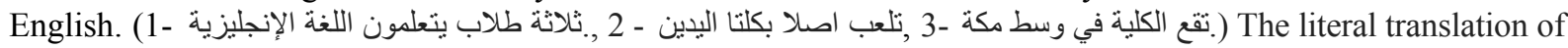
the examples shows that there aren't any English equivalents for 'are' and 'is' (forms of the verb 'Be') in the Arabic Language.

\subsubsection{Verb Tenses}

Errors of verb-tense is another area of concern for EFL learners. Some of the examples are given below:

Example 13: .... I wake up before my class ...

Correct sentence: .... I woke up before my class ...

Example 14: When I come into the school at the first day, ...

Correct sentence: When I came into the school on the first day, .......

Example 15: His father like the idea and book the tickets.

Correct sentence: His father liked the idea and booked the tickets.

Explanation: In these contexts of writing, the learners should have used the 'simple past' form of the verbs instead of the present tense. These errors are of the misinformation type which is pertaining to learner's lack of knowledge.

\subsubsection{Prepositions}

English and Arabic have some similarities and differences as well. The EFL learners tend to face some difficulties in the use of English prepositions that lead to the occurrence of such errors. Some of the examples are given below:

Example 16: I studied a medical college in another city ......

Correct sentence: I studied in a medical college in another city ......

Explanation: The preposition of place "in" was being by the learner which makes it an error of omission.

Example 17: You can join with the college bus.

Correct sentence: You can join the college bus.

Explanation: The learner used the preposition 'with' when it is not needed. Thus, it is an error of addition.

Example 18: He got revelation of the age of 40.

Correct sentence: He got revelation at the age of 40.

Explanation: The incorrect usage of the preposition in the above sentence leads to error of misinformation.

The learners might have omitted, added and misinformed the prepositions under the influence of L1. For instance, 
in Arabic, it is necessary to use a preposition if a relationship between two grammar entities is established in a sentence. It is evident in example 18 that the learner used the preposition unnecessarily. Therefore, the lack of knowledge of English prepositions may lead to a negative transfer from L1.

\subsubsection{Articles}

The participants of this study seemed to be confused about the usage of articles. There were errors with the use of a, an, the, and zero article. The errors which occurred were grouped into the categories of errors of omission, addition, and misinformation.

Example 19: .... and it is most difficult stage.....

Correct sentence: .... and it is the most difficult stage.....

Explanation: Definite article 'the' was omitted before the superlative degree 'most', resulting in the error of omission.

Example 20: ....to organise my time and have a complete knowledge of university.

Correct sentence: ....to organise my time and have complete knowledge of university.

Explanation: The indefinite article ' $a$ ' was added unnecessarily. It is an error of addition.

Example 21: When I was kid, I used to live in small city.

Correct sentence: When I was a kid, I used to live in a small city.

Explanation: The indefinite article ' $a$ ' was omitted twice before countable singular nouns in a sentence which makes it an error of omission.

Example 22: I went to ice mountain and

Correct sentence: I went to an ice mountain and

Explanation: The indefinite article 'an' was omitted before the countable singular noun which starts with a vowel sound (ice mountain). Thus, it's an error of omission.

The first example from the above-mentioned category may be the result of the lack of students' knowledge of this English grammar rule. This can be due to intralingual interference. The errors in other examples could be resulted due to L1 interference as there aren't any indefinite articles (a/an) in the grammar of Arabic. Also, the results of the study by Al-Khasawneh (2014) considered error of usage of articles as the most frequent errors.

\subsubsection{Subject-Verb Agreement}

Another area of concern in the English writings of the current study was the subject-verb agreement. It means subject and verb do not agree in number. The errors are evident as follows:

Example 23: There is a lot of malls and cafes.

Correct sentence: There are a lot of malls and cafes.

Explanation: The singular verb 'Be' (is) was used for plural subjects. It is an error of misinformation.

Example 24: She do it for me.

Correct sentence: She does it for me.

Explanation: As per English rule for the simple present tense, the third-person singular subjects use 's/es'. However, the learner used the rule applicable for the first-person singular, second- person singular/plural and third-person plural subjects. This is also an error of misinformation.

In example 23, the learner might be influenced by L1 rule i.e. the verb in the Arabic Language agrees with the first subject if it is followed by two or more subjects. If the first subject is plural, then the verb will be in the singular form. Nevertheless, the source of error in the other example might be an overgeneralization. Here, perhaps the error occurred due to the faulty application of the grammatical rule within L2.

\subsection{Sources of Errors}

\subsubsection{Interlingual Interference}

In the present study, the main sources of the errors are determined on the basis of careful and in-depth analysis of the errors and information found in students' writing, the questionnaires, interviews, and literature review. Interlingual interference is considered to be the major source of errors which accounts to more than half of the errors. The EFL learners tend to use literal translation of the linguistic rules of L1while they write in L2. Even 
other previous research indicated a similar result to the findings of this research (Rattanadilok Na Phuket \& Othman, 2015; Sermsook, Liamnimitr, \& Pochakorn, 2017). Therefore, similarities and differences between learners' L1 and L2 play a vital role in the language learning process.

\subsubsection{Intralingual Interference}

The next major source of errors is intralingual interference. The learners were confused about using the grammatical rules of English which leads them to commit errors in their writings. The findings of Zheng and Park (2013) study manifested the intralingual interference as the main source of errors.

\subsubsection{Inadequate Knowledge of L2}

The information gathered from the questionnaire and the interviews indicated that students encountered problems while composing their writing due to their limited knowledge of English grammatical rules and vocabulary. They expressed that the auto-check option on their electronic devices gradually developed a negative attitude towards learning to spell and mastering it. This led to the occurrence of several errors.

\subsubsection{Learners' Carelessness}

The source of the least committed errors is carelessness on the part of learners. During the interviews, learners admitted that some of the errors were due to their carelessness. Thus, to help learners to compose flawless writings we need to consider implementing some strategies to overcome learners' careless errors.

\section{Conclusion}

The importance of accuracy in writing in the real world motivated the researchers to conduct the current study. This study aimed at investigating the types, frequency, and sources of writing errors that can be committed by EFL students. The findings showed that students committed several writing errors which were basically grammatical in nature. These were the errors of omission, addition, misinformation, and misordering. Furthermore, the descriptive analysis of the results showed that interlingual interference and intralingual interference are the most important causes of errors in students' writing. In addition, limited knowledge of L2, inadequate practice in writing and carelessness of learners also contributed to the occurrence of errors. Even the results of the study by Sermsook, Liamnimitr and Pochakorn (2017) demonstrated the similar outcome. Hence, the study has pedagogical implications by addressing the issues that will help teachers to identify the areas of weaknesses and will help students to achieve their linguistic and learning objectives. At last, the aforementioned issues should be addressed in remedial English writing classes to get their optimum utility.

\section{Limitations}

The sample size of the study was small consisting of only 15 female students who were non-randomly selected, thus the results may not be generalised on the population.

\section{Acknowledgment}

We would like to thank authorities and colleagues at Umm Al Qura University (UQU) for supporting and encouraging us during the study. Last but not the least, thanks to the students at UQU who helped us in collecting data for the current study.

\section{References}

Al-Khasawneh, F. (2014). Error Analysis of Written English Paragraphs by Jordanian Undergraduate Students: A Case Study. International Journal of English Language, Linguistics and Humanities. Retrieved from http://www.ijellh.com/2014

Corder, S. P. (1967). The significance of learner's errors. International Review of Applied Linguistics in Language Teaching, 5(4), 161-170. https://doi.org/10.1515/iral.1967.5.1-4.161

Corder, S. P. (1974). Error Analysis. In J. P. B. Allen \& S. P. Corder (Eds.), Techniques in Applied Linguistics (The Edinburgh Course in Applied Linguistics: 3, pp. 122-154). London: Oxford University Press (Language and Language Learning).

Corder, S. P. (1981). Error analysis and interlanguages. Oxford: Oxford University Press.

Crystal, D. (1999). The penguin dictionary of language (2nd ed.). Penguin.

Dulay, H. C., Burt, M. K., \& Krashen, S. D. (1982). Language two. New York: Oxford University Press.

James, C. (1998). Errors in language learning and use: Exploring error analysis. New York: Routledge.

Khansir, A. A. (2013). Error analysis and second language writing. Theory and Practice in Language Studies, 


\section{3(2), 363-370. https://doi.org/10.4304/tpls.3.2.363-370}

Khoso, A. R., Pathan, H., \& Shah, S. W. (2018). Identify the Grammatical Errors Committed by EFL Learners: A Study of Public Sector Universities of Sindh, Pakistan. Journal of Literature, Language and Linguistics, 47, 66-71. Retrieved from https://iiste.org/Journals/index.php/JLLL/article/view/43858/45191

Rattanadilok Na Phuket, P., \& Othman, N. B. (2015). Understanding EFL students' errors in writing. Journal of Education and Practice, 6(32), 99-106. http://iiste.org/Journals/index.php/JEP

Sermsook, K., Liamnimitr, J., \& Pochakorn, R. (2017). An Analysis of Errors in Written English Sentences: A Case Study of Thai EFL Students. English Language Teaching, 3(10), 101-110. https://doi.org/10.5539/elt.v10n3p101

Walsh, K. (2010). The importance of writing skills: Online tools to encourage success. Retrieved from http://www.emergingedtech.com/2010

Zheng, C., \& Park, T. (2013). An analysis of errors in English writing made by Chinese and Korean university students. Theory and Practice in Language Studies, 3(8), 1342-1351. https://doi.org/10.4304/tpls.3.8.1342-1351

\section{Copyrights}

Copyright for this article is retained by the author, with first publication rights granted to the journal.

This is an open-access article distributed under the terms and conditions of the Creative Commons Attribution license (http://creativecommons.org/licenses/by/4.0/). 